\title{
GPR126: A novel candidate gene implicated in autosomal recessive intellectual disability
}

\author{
Masoumeh Hosseini ${ }^{1}$ | Zohreh Fattahi ${ }^{1}$ | Seyedeh Sedigheh Abedini ${ }^{1}$ | Hao Hu${ }^{2}$ | \\ Hans-H. Ropers ${ }^{2}$ | Vera M. Kalscheuer ${ }^{2}$ | Hossein Najmabadi ${ }^{1}$ | Kimia Kahrizi ${ }^{1}$
}

${ }^{1}$ Genetics Research Center, University of Social Welfare and Rehabilitation Sciences, Tehran, Iran

${ }^{2}$ Department Human Molecular Genetics, Max-Planck-Institute for Molecular Genetics, Berlin, Germany

\section{Correspondence}

Kimia Kahrizi, Genetics Research Center, University of Social Welfare and Rehabilitation Sciences, Tehran 19857, Iran.

Emails: kahrizi@yahoo.com;

hnajm12@yahoo.com

Funding information

National Institute for Medical Research

Development, Grant/Award Numbers:

957060, 958715; Iranian National Science

Foundation, Grant/Award Numbers: 950022 , 92038458; FP7 project GENCODYS, Grant/ Award Number: 241995

\begin{abstract}
Intellectual disability (ID), a genetically and clinically heterogeneous disorder, affects $1 \%-3 \%$ of the general population and is a major health problem, especially in developing countries and in populations with a high frequency of consanguineous marriage. Using whole exome sequencing, a homozygous missense variation (c.3264G>C, p.W1088C) in a plausible disease causing gene, GPR126, was identified in two patients presenting with profound ID, severe speech impairment, microcephaly, seizures during infancy, and spasticity accompanied by cerebellar hypoplasia. The role of GPR126 in radial sorting and myelination in Schwann cells suggests a mechanism of pathogenesis for ID. Involvement of GPR126 in lethal congenital contracture syndrome 9 has been identified previously, but this is the first report of a plausible candidate gene, GPR126, in ID.
\end{abstract}

\section{KEYWORDS}

cerebellar hypoplasia, GPR126, intellectual disability, microcephaly

\section{1 | INTRODUCTION}

Intellectual disability (ID) is commonly associated with other comorbidities and when this is the case, it is identified as syndromic ID (SID). Microcephaly and spasticity with or without seizure are prevalent characteristics of SID (Kahrizi \& Najmabadi, 2015; Najmabadi et al., 2011).

Because of high levels of heterogeneity in ID, until recently, and before the introduction of next generation sequencing (NGS) technology, little was known about the molecular basis of ID. NGS has made it possible to recognize new genes associated with ID and over 700 genes have been identified to be implicated in this disorder. So far, fewer than 600 of these genes have been associated with autosomal recessive intellectual disability (ARID), which shows the importance of ARID gene identification, especially in populations with frequent parental consanguinity (Ansar et al., 2017; Najmabadi et al., 2011).

We present here the first report of a plausible disease causing gene, GPR126, in an Iranian family with two patients suffering from profound ID, severe speech impairment, microcephaly, seizures during infancy, and spasticity accompanied by cerebellar hypoplasia and widening of the fourth ventricle. Both patients were homozygous for c.3264G>C, p.W1088C missense mutation. This mutation has been identified in a cohort study on 404 Iranian families with ID.

\section{MATERIALS AND METHODS}

\section{1 | Clinical findings}

The two male patients (III:7 and III:8) were from first cousin healthy parents living in a province in the central part of Iran (Figure 1a).

Patient III:7 was the younger male patient with unremarkable pregnancy, delivery, and infancy. He started to sit and stand at a normal age but after a generalized seizure at 13 months, he never walked. When he was 16 years, his occipitofrontal circumference (OFC) was $50 \mathrm{~cm}$ (-4 standard deviation (SD)) and height was $133 \mathrm{~cm}$ (-4.8 standard deviation (SD)). He was not able to sit or stand, he was paraplegic from childhood, and had spasticity in the upper and lower extremities associated with joint contracture and muscle atrophy (Figure 1b).

He showed a reaction to sound and light but he had no speech. Intelligence Quotient (IQ) testing was not possible because of lack of participation. IQ was estimated within the range 20-25. Cranial 


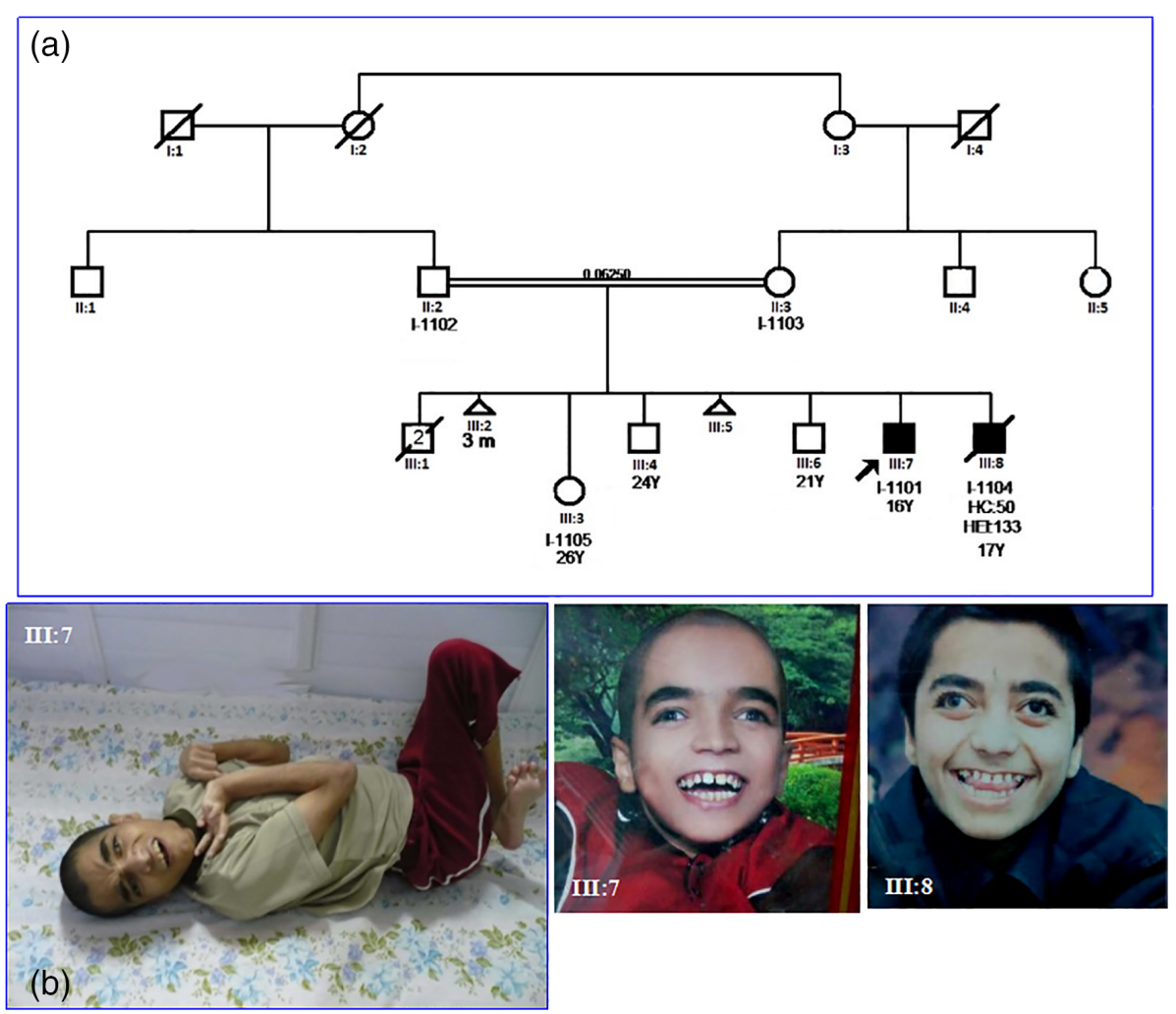

FIGURE 1 (a) Pedigree of the family. Square symbols, male; round symbols, female. Filled symbols represent affected individuals. (b) Photograph of patients III:7 and III:8 [Color figure can be viewed at wileyonlinelibrary.com]

magnetic resonance imaging (MRI) obtained at age 16 showed cerebellar hypoplasia and widening of the fourth ventricle (Figure 2).

Patient III:8 was born at term after an uneventful pregnancy and with normal birth measurements that were not documented. He had a normal development to 12 months and then had a history of seizures since 12 months that were poorly controlled by antiepileptic medication. He could never stand or walk, he never started to say one single word, and he responded to sound and light. When he was 17 years, his OFC was $50 \mathrm{~cm}$ (-4 standard deviation (SD)) and height was $133 \mathrm{~cm}$ (-5.2 standard deviation (SD)). He was paraplegic from childhood and had spasticity in the upper and lower extremities associated with joint contracture and muscle atrophy. The patient attended a special needs school at age 13. IQ testing was not possible because of lack of participation. IQ was estimated within the range 20-25. He died at age 19 from an unknown cause during his stay at the special needs school.

\subsection{Materials and methods}

One affected patient was selected for sequencing. Genomic DNA (gDNA) was extracted from peripheral blood, the quality of which was controlled by a NanoDrop2000 spectrophotometer (Thermo Scientific, Thermo Fisher Scientific, Wilmington, Delaware, USA), and approximately $2 \mu \mathrm{g}$ gDNA was used for constructing deep sequencing libraries and whole exome sequencing (WES) on the Illumina HiSeq2000 sequence was employed.

We analyzed WES data with an in-house developed and published pipeline called Medical Resequencing Analysis Pipeline (Hao et al., 2014).

All potentially ID-causing variants detected by WES were validated by Sanger sequencing and cosegregation studies were performed, including all available and informative family members. To further enrich them for pathogenic mutations, variants were also filtered in several other ways, including pathogenicity prediction for missense variants using four established prediction tools (PolyPhen2, SIFT, MutationTaster, CADD), and selected for absence or very low allele frequencies in the ExAC Database and our own in-house cohort which largely consists of Iranian families.

\section{3 | RESULTS}

WES revealed a homozygous novel missense mutation, c.3264G>C, p. W1088C (NM_020455), in exon 3 of GPR126 gene which was verified in the family by Sanger sequencing. This mutation was not present in either our in-house exomes or any public variant databases. Based on data from various bioinformatics prediction tools, this variant was predicted to be pathogenic (Figure 3).

Using the have (y)our protein explained (HOPE) program, it was predicted that the mutated residue was located in the seventransmembrane (7TM) domain and was highly evolutionarily conserved (Figure 4). The mutant residue was smaller than the wild-type residue which may affect its contacts with the lipid membrane (Venselaar, te Beek, Kuipers, Hekkelman, \& Vriend, 2010).

\section{4 | DISCUSSION}

In the current study, filtering the WES data of an Iranian ID family resulted in the identification of a plausible ID gene, GPR126 

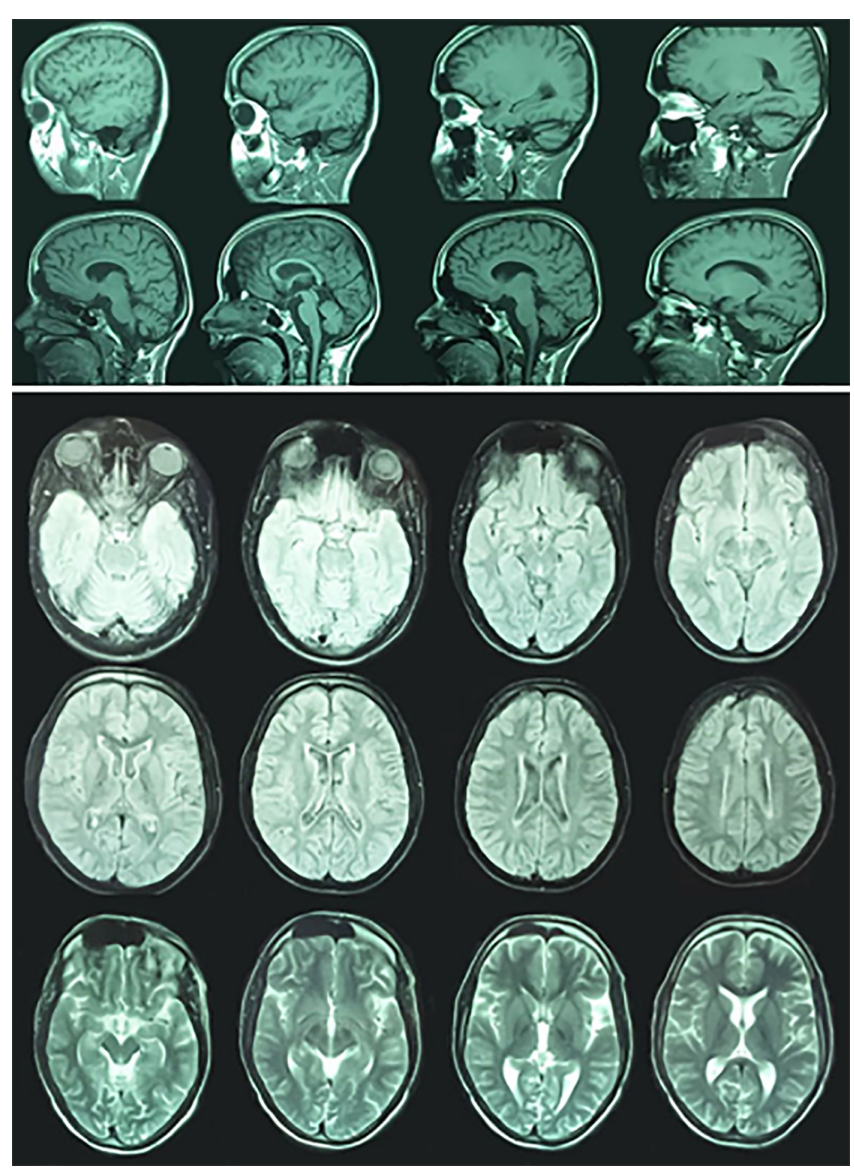

FIGURE 2 Magnetic resonance imaging from the proband (III:7).

(a) T1-weighted images in sagittal view showed mild cerebellar hypoplasia. (b) T2-weighted images in cross sectional (axial) view showed widening of the fourth ventricle and sulci. Supratentorial ventricles are normal [Color figure can be viewed at wileyonlinelibrary.com]

(ADGRG6). This variant was predicted to be a pathogenic variant and was compatible with the phenotype of the family. The gene has not been reported previously for ID and is predicted to be involved in Gprotein coupled receptor (GPCR) activity and signaling pathway, collagen binding, extracellular matrix binding, laminin binding, and the cell surface receptor signaling pathway (Gene Ontology Database: www. geneontology.org). Most G-proteins and GPCRs are expressed in the brain. They play important roles in brain function and neural development by mediating synaptic transduction and synaptic formation, respectively (Vassilatis et al., 2003). Furthermore, alterations in GPCR signaling are involved in a variety of neurological disorders, including dysmorphogenesis, psychosis, and/or mental disabilities (Allen et al., 1998; D'Adamo et al., 1998; Keverne \& Curley, 2004; Kirsch et al., 2005; Lim, Bielsky, \& Young, 2005). These findings support our current result that mutation in GPR126 could possibly lead to an ID phenotype.

GPR126 is a member of the adhesion G-protein-coupled receptors (aGPCRs), which play important roles in neural development. Potentially, mutation in aGPCR CELSR1 (also known as ADGRC1) results in a defect in neural tube closure. GPR56 (ADGRG1), which regulates cell-matrix adhesion in neural cells, is involved in the complexity of the neocortex. Mutations in GPR56 can cause bilateral frontal parietal polymicrogyria and knock out GPR56 mice showed defects in the cerebral cortex and cerebellum (Hamann et al., 2015; Langenhan, Aust, \& Hamann, 2013; Langenhan \& Schöneberg, 2016; Paavola \& Hall, 2012).

The human GPR126, an orphan receptor, spans 26 exons and is located on chromosome 6q24.1; this gene is a member of the ADGRG subfamily. The ADGRG family consists of CUB, PTX, HBD, GAIN domains, and a C-terminal 7TM domain. GPR126, like many aGPCR families, comprises an N-terminal GPCR proteolytic site motif which cleaves this receptor in the endoplasmic reticulum as part of receptor processing (Demberg et al., 2017; Paavola, Sidik, Zuchero, Eckart, \& Talbot, 2014; Stoveken, Hajduczok, Xu, \& Tall, 2015).

GPR126 has been indicated to be required for the development of Schwann cell (SC) as well as radial sorting and myelination of peripheral nerves by SCs in zebrafish and mice (Langenhan \& Schöneberg, 2016; Mogha et al., 2013, 2016; Patra et al., 2013; Waller-Evans et al., 2010).

During mice embryogenesis, GPR126 is expressed in the heart, somites, lung, and endothelial cells and as demonstrated in knock down and knock out experiments, is essential in neural, cardiac, and ear development. In zebrafish, this gene expression was observed in SCs of the posterior lateral line nerve during the embryonic stage and adulthood. Persistent expression of GPR126 during adulthood in SCs can signify the putative function of this gene in the mature nerve; however, its role has not been clarified (Birchmeier, 2011; Bjarnadóttir, Fredriksson, \& Schiöth, 2007; Monk et al., 2009; Patra et al., 2013). GPR126 is also required for regeneration of axons following injuries (Camacho et al., 2015).

Based on recent studies on the regulation of myelin formation by SCs, GPR126 binds Gas proteins, which consequently increases CAMP level and stimulates downstream protein kinase A (PKA) signaling. The process finally leads to the expression of myelination stimulation genes. Monk et al. reported a severe congenital hypomyelinating peripheral neuropathy, delayed axonal sorting, and arrested SCs in the promyelinating stage in GPR126-/- mutant mice. GPR126 $6^{-/-}$mouse revealed axon degeneration, defects in radial sorting, myelination, and limb contracture, and various experiments demonstrated that myelination defects are rescued by increasing the CAMP level or PKA signaling (Mogha et al., 2016; Patra et al., 2013; Waller-Evans et al., 2010).

Pathogenic variants in GPR126 protein lead to lethal congenital contracture syndrome 9 (LCCS9) defined by degeneration of anterior horn neurons, extreme skeletal muscle atrophy congenital nonprogressive joint contractures and dysmorphic facial features. LCCS9 can overlap with arthrogryposis multiplex congenita (AMC), which is characterized by the presence of contractures across at least two major joints (Ravenscroft et al., 2015).

Ravenscroft et al. have reported three consanguineous families affected by lethal AMC. In all three cases, death occurred at $1 \mathrm{hr}$ of life at 20,31 , and 36 weeks of gestation. In the fetus who survived until 36 weeks of gestation, severe arthrogryposis involving large and small joints, dysmorphic facial features including a triangular face, micrognathia, a thin upper lip, low-set ears, anteverted nares, and a depressed nasal bridge were noted. Interestingly, our family share some features with this family such as joint contractures, spasticity, depressed nasal bridge, thin upper lip, and low-set ears. Albeit these two families have some characteristics in common, Iranian patients 


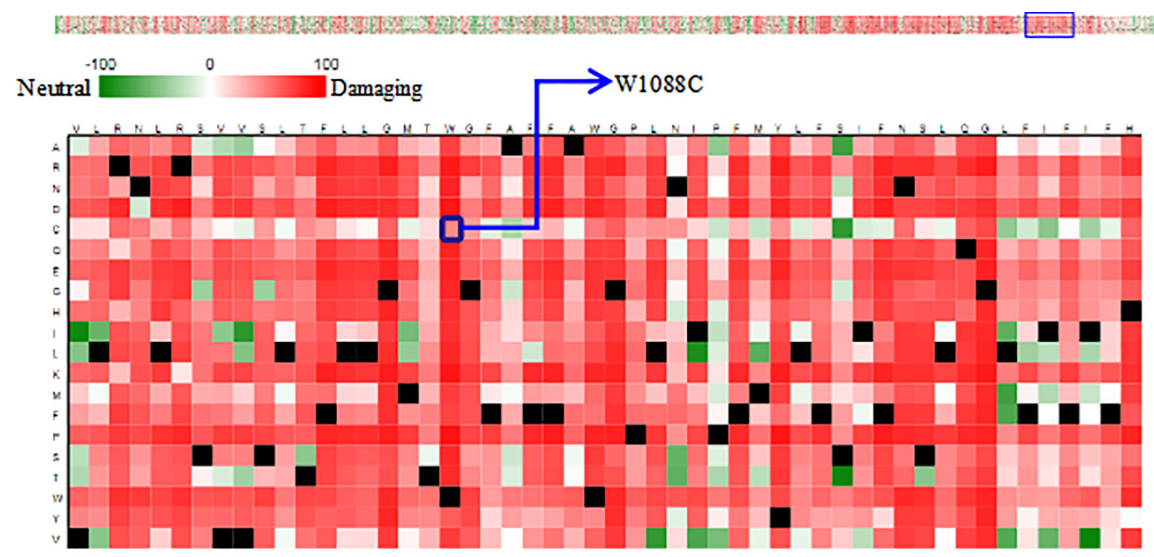



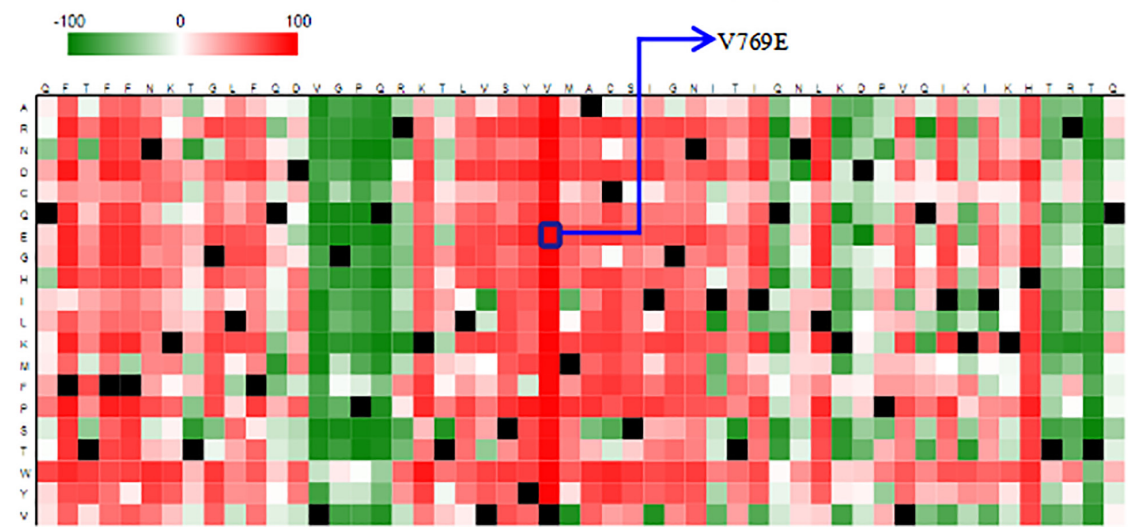

FIGURE 3 Global analysis for the effect of mutations in GPR126 using snap2 program in PredictProtein site [Color figure can be viewed at wileyonlinelibrary.com]

also showed strabismus, hypertelorism, smiling face, and widely spaced teeth and as described in the clinical findings section, they also suffer from profound ID, severe speech impairment, microcephaly, seizures during infancy, and brain MRI findings which discriminate our patients from previously reported LCCS9 cases.

The missense change identified in the current study is localized in the 7TM domain, which is a highly conserved motif in the GPR126 protein, a common structural signature of seven hydrophobic transmembrane (TM) segments, with an extracellular amino terminus and an intracellular carboxyl terminus (Kobilka, 2007). It has been proposed that ligand binding to extracellular domain of GPCR leads to conformational changes in TM domains, conversion of receptor into the active state, and finally induction of 7TM-dependent signaling. Thus, mutations in the TM domain might cause deleterious effects (Tuteja, 2009). On the other hand, studies of ligand binding to GPCR have indicated that proteins and peptide hormones often bind to the amino terminus and extracellular sequences joining the TM domains; therefore, it is predicted that this variant would likely disrupt the contacts with the peptide hormones and proteins (Kobilka, 2007). In addition, the mutant residue is smaller than the wild-type residue which may affect the contacts with the lipid membrane (Venselaar et al., 2010).

The mutation (c.2306T>A, p.Val769Glu) detected by Ravenscroft et al. occurred in GAIN domain. Previous data indicated that autoproteolytic cleavage occurs in GAIN domain of GPR126 which is crucial

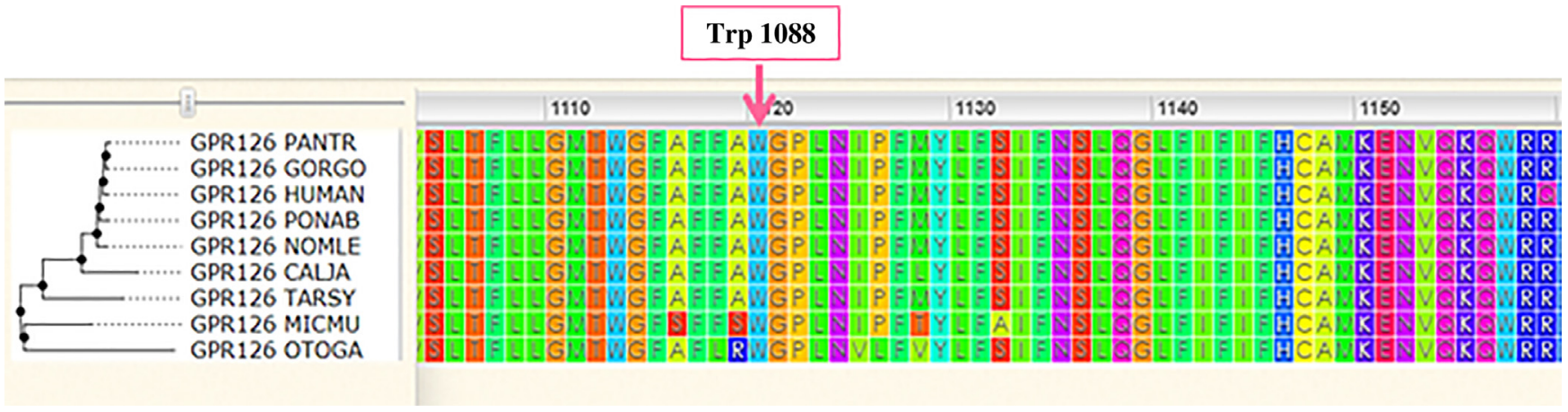

FIGURE 4 Multiple sequence alignment demonstrating that the Tryptophan in position 1,088 is conserved in different species [Color figure can be viewed at wileyonlinelibrary.com] 

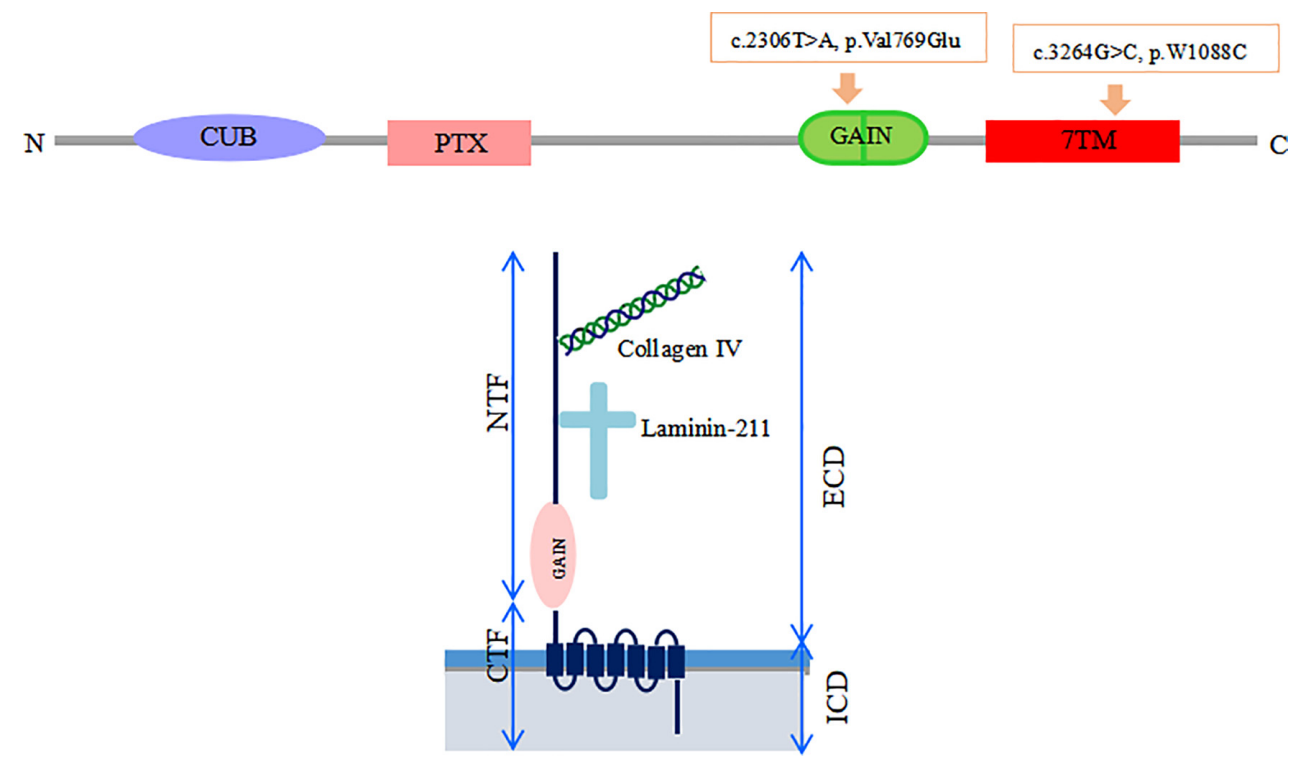

FIGURE 5 Schematic diagram of GPR126 domains and the model suggested for its interaction with Laminin-211 [Color figure can be viewed at wileyonlinelibrary.com]

for activating of GPR126 signaling. Based on these data and regarding the mutation identified in AMC cases, they have concluded that the missense mutation probably destroys autoproteolytic cleavage of GPR126 (Ravenscroft et al., 2015). Thus, it might be hypothesized that different phenotypes observed in these families are because of involvement of various GPR126 domains.

In the study by Ravenscroft et al. (2015), peripheral nerves in affected individuals from one of the families investigated were found to lack myelin basic protein (MBP), suggesting that GPR126 is critical for myelination of peripheral nerves in humans (Defrancesco et al., 2014). The main neurological manifestations of Iranian patients including spasticity, joint contracture, and reduced deep tendon reflexes indicate myelin involvement and the essential role of GPR126 in the formation of myelin sheaths in peripheral nerve cells as well.

Laminin-211 and collagen IV, two components of basal lamina, have been identified as GPR126 binding partners, and these ligands interact with different domains in NTF of GPR126 (Figure 5) (Monk et al., 2015). Laminin-211 interacts with the GAIN domain of GPR126 which modulates Stachel-mediated activity of this protein. Stachel is a linker sequence of 20 amino acids connected to 7TM and is exposed after aGPCR cleavage and subsequent receptor activation (Langenhan, Piao, \& Monk, 2016 Langenhan \& Schöneberg, 2016; Petersen et al., 2015). Collagen IV binds to CUB and PTX domains of GPR126 and activates its signaling function through increasing the cAMP level in SCs of rodents (Camacho et al., 2015; Langenhan \& Schöneberg, 2016; Paavola et al., 2014).

Laminin-211 (also known as merosin) is composed of one $\alpha 2$, one $\beta 1$, and one $\gamma 1$ subunit which are encoded by different genes. The $\alpha 2$ chain is encoded by the LAMA2 gene and mutations in this gene cause laminin $\alpha 2$-related congenital muscular dystrophy or congenital muscular dystrophy Type 1A (MDC1A). MDC1A is characterized by generalized hypotonia and muscle weakness from birth, joint contracture, delayed motor milestone, and white matter abnormalities with an increased risk of neuronal migration defects, seizure, and ID (Geranmayeh et al., 2010; Ghidinelli et al., 2017; Løkken, Born, Duno, \& Vissing, 2015; Marques et al., 2014). The role of LAMA2 in thickness and folding of myelin sheaths, its implication in synaptogenesis during development and the phenotype of patients suffering from MDC1A suggest that GPR126 may play its role through interaction with LAMA2.

In addition to the well-known demyelinating and dysmyelinating diseases such as multiple sclerosis, neuromyelitis optica, and the leukodystrophies, myelin deficits resulting from altered glial structure/ function and or glial/neuronal interactions are seen in human psychiatric disorders and developmental disorders including autism spectral disorder, bipolar disorder, language disorders, stuttering, sensory processing delay disorder (Owen et al., 2013), attention deficit hyperactivity disorder (Geranmayeh et al., 2010; Wu, Gau, Lo, \& Tseng, 2014), and Rett syndrome (Mahmood et al., 2010). Adult onset neurodegenerative diseases including Alzheimer's, Parkinson's, and amyotrophic lateral sclerosis (Defrancesco et al., 2014; Kang et al., 2013; Kim et al., 2013) also show myelin pathology. Inherited disorders affecting structural genes in myelin are the cause of diseases such as CharcotMarie-Tooth disease, Dejerine Sottas syndrome, and PelizaeusMarzbacher disease. Alexander disease is caused by a genetic defect in astrocytes and this results in severe hypomyelination, mental retardation, and death at a young age. These findings have been reported before in relation to mental retardation, and support the pathogenic role of the variant in GPR126 encountered in this study.

The current study is the first report of an ARID involving the GPR126 gene, which has already been implicated in LCCS9. Based on the role of GPR126, its interacting partners and clinical manifestations of the patients, the variant in the GPR126 gene could be the causative variant in this family and could be responsible for the patients' phenotype.

\section{5 | CONCLUSION}

The identification of pathogenic variation in GPR126 in the current study suggests the potential importance of the particular pathways associated with this gene involved in cognitive dysfunction. In the 
absence of functional data, the definitive role of variation in this gene cannot be ascertained with certainty. However, after exome sequencing and segregation analysis of all of the filtered variants, the currently reported variant was the only one that segregated with the phenotype in the family. Therefore, it is proposed that this variation could be the most likely cause of ID in the family studied. The finding of additional variations in this gene in other families with ID could validate the current results. In addition, functional studies could also define the detailed pathophysiological mechanism of this mutation and validate this result.

\section{ACKNOWLEDGMENTS}

The authors acknowledge the contribution of patients and their family members in this study. The authors also thank the Deputy of Research and Technology in Ministry of Health and Medical Education, Islamic Republic of Iran, the Iranian National Elite Foundation and the Iranian Science Elite Federation for scientific supports. This study was supported by the European Union through FP7 project GENCODYS (grant no. 241995), the Iranian National Science Foundation (grant no. 92038458 and 950022), and the National Institute for Medical Research Development (grant no. 958715 and 957060).

\section{CONFLICT OF INTEREST}

The authors declared that they have no conflict of interest.

\section{ORCID}

Kimia Kahrizi (ID) https://orcid.org/0000-0002-6587-7706

\section{REFERENCES}

Allen, K. M., Gleeson, J. G., Bagrodia, S., Partington, M. W. MacMillan, J. C., Cerione, R. A., \& Walsh, C. A. (1998). PAK3 mutation in nonsyndromic X-linked mental retardation. Nature Genetics, 20, 25. https://doi.org/10.1038/1675

Ansar, M., Riazuddin, S., Sarwar, M. T., Makrythanasis, P., Paracha, S. A., Iqbal, Z., ... Antonarakis, S. E. (2017). Biallelic variants in LINGO1 are associated with autosomal recessive intellectual disability, microcephaly, speech and motor delay. Genetics in Medicine, 20, 778-784 https://doi.org/10.1038/gim.2017.113

Birchmeier, C. (2011). Growth factors in development (Vol. 97). San Diego, USA: Academic Press.

Bjarnadóttir, T. K., Fredriksson, R., \& Schiöth, H. B. (2007). The adhesion GPCRs: A unique family of $G$ protein-coupled receptors with important roles in both central and peripheral tissues. Cellular and Molecular Life Sciences, 64, 2104-2119. https://doi.org/10.1007/ s00018-007-7067-1

Camacho, A., Núñez, N., Dekomien, G., Hernández-Laín, A., de Aragón, A. M., \& Simón, R. (2015). LAMA2-related congenital muscular dystrophy complicated by West syndrome. European Journal of Paediatric Neurology, 19, 243-247.

Adamo D., Menegon P., A. Lo Nigro, C., Grasso, M., Gulisano, Tamanini, F., \& Toniolo, D. (1998). Mutations in GDI1 are responsible for X-linked non-specific mental retardation. Nature Genetics, 19, 134-139. https://doi.org/10.1038/487

Defrancesco, M., Egger, K., Marksteiner, J., Esterhammer, R., Hinterhuber, H., Deisenhammer, E. A., \& Schocke, M. (2014). Changes in white matter integrity before conversion from mild cognitive impairment to Alzheimer's disease. PLoS ONE, 9, e106062. https://doi. org/10.1371/journal.pone.0106062
Demberg, L. M., Winkler, J., Wilde, C., Simon, K. -U., Schön, J., Rothemund, S., \& Liebscher, I. (2017). Activation of adhesion G protein-coupled receptors: Agonist specificity of Stachel sequence-derived peptides. Journal of Biological Chemistry, 292, 4383-4394. https://doi.org/10.1074/jbc.M116.763656

Geranmayeh, F., Clement, E., Feng, L. H., Sewry, C., Pagan, J., Mein, R., \& Muntoni, F. (2010). Genotype-phenotype correlation in a large population of muscular dystrophy patients with LAMA2 mutations. Neuromuscular Disorders, 20, 241-250. https://doi.org/10.1016/j.nmd.2010. 02.001

Ghidinelli, M., Poitelon, Y., Shin, Y. K., Ameroso, D., Williamson, C., Ferri, C., \& Feltri, M. L. (2017). Laminin 211 inhibits protein kinase A in Schwann cells to modulate neuregulin 1 type III-driven myelination. PLoS Biology, 15, e2001408. https://doi.org/10.1371/journal.pbio. 2001408

Hamann, J., Aust, G., Araç, D., Engel, F. B., Formstone, C., Fredriksson, R., \& Schiöth, H. B. (2015). International Union of Basic and Clinical Pharmacology. XCIV. Adhesion G protein-coupled receptors. Pharmacological Reviews, 67, 338-367. https://doi.org/10.1124/ pr.114.009647

Hao, H., Wienker, T.F., Luciana, M., M., K. V., Kimia, K., Hossein, N., \& Hilger, R. H. (2014). Integrated sequence analysis pipeline provides one-stop solution for identifying disease-causing mutations. Human Mutation, 35, 1427-1435. https://doi.org/10.1002/humu.22695

Kahrizi, K., \& Najmabadi, H. (2015). Genetics of recessive cognitive disorders. eLS. https://doi.org/10.1002/9780470015902.a0025835

Kang, S. H., Li, Y., Fukaya, M., Lorenzini, I., Cleveland, D. W., Ostrow, L. W., \& Bergles, D. E. (2013). Degeneration and impaired regeneration of gray matter oligodendrocytes in amyotrophic lateral sclerosis. Nature Neuroscience, 16, 571-579. https://doi.org/10.1038/ nn.3357

Keverne, E. B., \& Curley, J. P. (2004). Vasopressin, oxytocin and social behaviour. Current Opinion in Neurobiology, 14, 777-783. https://doi. org/10.1016/j.conb.2004.10.006

Kim, H. J., Kim, S. J., Kim, H. S., Choi, C. G., Kim, N., Han, S., \& Lee, C. S. (2013). Alterations of mean diffusivity in brain white matter and deep gray matter in Parkinson's disease. Neuroscience Letters, 550, 64-68. https://doi.org/10.1016/j.neulet.2013.06.050

Kirsch, P., Esslinger, C., Chen, Q., Mier, D., Lis, S., Siddhanti, S., \& Meyer-Lindenberg, A. (2005). Oxytocin modulates neural circuitry for social cognition and fear in humans. The Journal of Neuroscience, 25, 11489-11493. https://doi.org/10.1523/jneurosci.3984-05.2005

Kobilka, B. K. (2007). G protein coupled receptor structure and activation. Biochimica et Biophysica Acta (BBA)-Biomembranes, 1768, 794-807. https://doi.org/10.1016/j.bbamem.2006.10.021

Langenhan, T., Aust, G., \& Hamann, J. (2013). Sticky signaling-Adhesion class $\mathrm{G}$ protein-coupled receptors take the stage. Science Signaling, 6, re3. https://doi.org/10.1126/scisignal.2003825

Langenhan, T., Piao, X., \& Monk, K. R. (2016). Adhesion G protein-coupled receptors in nervous system development and disease. Nature Reviews Neuroscience, 17, 550-561.

Langenhan, T., \& Schöneberg, T. (2016). Adhesion G protein-coupled receptors: Molecular, physiological and pharmacological principles in health and disease (Vol. 234). New York, USA: Springer International Publishing.

Lim, M. M., Bielsky, I. F., \& Young, L. J. (2005). Neuropeptides and the social brain: Potential rodent models of autism. International Journal of Developmental Neuroscience, 23, 235-243. https://doi.org/10.1016/j. ijdevneu.2004.05.006

Løkken, N., Born, A. P., Duno, M., \& Vissing, J. (2015). LAMA2-related myopathy: Frequency among congenital and limb-girdle muscular dystrophies. Muscle \& Nerve, 52, 547-553.

Mahmood, A., Bibat, G., Zhan, A. -L., Izbudak, I., Farage, L., Horska, A., \& Naidu, S. (2010). White matter impairment in Rett syndrome: Diffusion tensor imaging study with clinical correlations. American Journal of Neuroradiology, 31, 295-299. https://doi.org/10.3174/ajnr.A1792

Marques, J., Duarte, S. T., Costa, S., Jacinto, S., Oliveira, J., Oliveira, M. E., \& Evangelista, T. (2014). Atypical phenotype in two patients with LAMA2 mutations. Neuromuscular Disorders, 24, 419-424. https://doi.org/10.1016/j.nmd.2014.01.004

Mogha, A., Benesh, A. E., Patra, C., Engel, F. B., Schöneberg, T., Liebscher, I., \& Monk, K. R. (2013). Gpr126 functions in Schwann cells 
to control differentiation and myelination via G-protein activation. The Journal of Neuroscience, 33, 17976-17985. https://doi.org/10.1523/ jneurosci.1809-13.2013

Mogha, A., Harty, B. L., Carlin, D., Joseph, J., Sanchez, N. E., Suter, U., \& Monk, K. R. (2016). Gpr126/Adgrg6 has Schwann cell autonomous and nonautonomous functions in peripheral nerve injury and repair. The Journal of Neuroscience, 36, 12351-12367. https://doi.org/10.1523/ jneurosci.3854-15.2016

Monk, K. R., Hamann, J., Langenhan, T., Nijmeijer, S., Schöneberg, T., \& Liebscher, I. (2015). Adhesion G protein-coupled receptors: From in vitro pharmacology to in vivo mechanisms. Molecular Pharmacology, 88, 617-623. https://doi.org/10.1124/mol.115.098749

Monk, K. R., Naylor, S. G., Glenn, T. D., Mercurio, S., Perlin, J. R., Dominguez, C., \& Talbot, W. S. (2009). A G protein-coupled receptor is essential for Schwann cells to initiate myelination. Science, 325, 1402-1405.

Najmabadi, H., Hu, H., Garshasbi, M., Zemojtel, T., Abedini, S. S., Chen, W., \& Ropers, H. H. (2011). Deep sequencing reveals 50 novel genes for recessive cognitive disorders. Nature, 478, 57-63. https:// doi.org/10.1038/nature10423

Owen, J. P., Marco, E. J., Desai, S., Fourie, E., Harris, J., Hill, S. S., \& Mukherjee, P. (2013). Abnormal white matter microstructure in children with sensory processing disorders. Neuroimage: Clinical, 2, 844-853. https://doi.org/10.1016/j.nicl.2013.06.009

Paavola, K. J., \& Hall, R. A. (2012). Adhesion G protein-coupled receptors: Signaling, pharmacology, and mechanisms of activation. Molecular Pharmacology, 82, 777-783. https://doi.org/10.1124/mol.112.080309

Paavola, K. J., Sidik, H., Zuchero, J. B., Eckart, M., \& Talbot, W. S. (2014). Type IV collagen is an activating ligand for the adhesion G protein-coupled receptor GPR126. Science Signaling, 7, ra76-ra76. https://doi.org/10.1126/scisignal.2005347

Patra, C., van Amerongen, M. J., Ghosh, S., Ricciardi, F., Sajjad, A., Novoyatleva, T., \& Engel, F. B. (2013). Organ-specific function of adhesion G protein-coupled receptor GPR126 is domain-dependent. Proceedings of the National Academy of Sciences, 110, 16898-16903. https://doi.org/10.1073/pnas.1304837110

Petersen, S. C., Luo, R., Liebscher, I., Giera, S., Jeong, S. -J., Mogha, A., \& Monk, K. R. (2015). The adhesion GPCR GPR126 has distinct, domain-dependent functions in Schwann cell development mediated by interaction with Laminin-211. Neuron, 85, 755-769. https://doi. org/10.1016/j.neuron.2014.12.057

Ravenscroft, G., Nolent, F., Rajagopalan, S., Meireles, A. M., Paavola, K. J., Gaillard, D., \& Krivanek, M. (2015). Mutations of GPR126 are responsible for severe arthrogryposis multiplex congenita. The American Journal of Human Genetics, 96, 955-961. https://doi.org/10.1016/j.ajhg.2015.04.014

Stoveken, H. M., Hajduczok, A. G., Xu, L., \& Tall, G. G. (2015). Adhesion G protein-coupled receptors are activated by exposure of a cryptic tethered agonist. Proceedings of the National Academy of Sciences, 112, 6194-6199. https://doi.org/10.1073/pnas.1421785112

Tuteja, N. (2009). Signaling through G protein coupled receptors. Plant Signaling \& Behavior, 4, 942-947.

Vassilatis, D. K., Hohmann, J. G., Zeng, H., Li, F., Ranchalis, J. E., Mortrud, M. T., \& Gaitanaris, G. A. (2003). The G protein-coupled receptor repertoires of human and mouse. Proceedings of the National Academy of Sciences, 100, 4903-4908. https://doi.org/10.1073/pnas. 0230374100

Venselaar, H., te Beek, T. A., Kuipers, R. K., Hekkelman, M. L., \& Vriend, G. (2010). Protein structure analysis of mutations causing inheritable diseases. An e-science approach with life scientist friendly interfaces. BMC Bioinformatics, 11, 548. https://doi.org/10.1186/1471-2105-11-548

Waller-Evans, H., Prömel, S., Langenhan, T., Dixon, J., Zahn, D., Colledge, W. H., \& Russ, A. P. (2010). The orphan adhesion-GPCR GPR126 is required for embryonic development in the mouse. PLOS ONE, 5, e14047. https://doi.org/10.1371/journal.pone.0014047

Wu, Y. H., Gau, S. S., Lo, Y. C., \& Tseng, W. Y. (2014). White matter tract integrity of frontostriatal circuit in attention deficit hyperactivity disorder: Association with attention performance and symptoms. Human Brain Mapping, 35, 199-212. https://doi.org/10.1002/hbm.22169

How to cite this article: Hosseini M, Fattahi Z, Abedini SS, et al. GPR126: A novel candidate gene implicated in autosomal recessive intellectual disability. Am J Med Genet Part A. 2019; 179A:13-19. https://doi.org/10.1002/ajmg.a.40531 